\title{
MODEL-BASED QUANTUM-CHEMICAL STUDY OF THE UPTAKE OF SOME POLYCHLORINATED POLLUTANT COMPOUNDS BY ZUCCHINI SUBSPECIES
}

\author{
CAMILA BARAHONA-URBINA, SOLANGE NUÑEZ-GONZALEZ AND JUAN S. GÓMEZ-JERIA*
}

Department of Chemistry, Faculty of Sciences, University of Chile. Las Palmeras 3425, Nuñoa, Santiago, Chile.

(Received: September 10, 2012 - Accepted: October 12, 2012)

\begin{abstract}
We report the results of a search of formal relationships between accumulation data and molecular structure for some pollutant molecules (polychlorinated dibenzo-p-dioxins, polychlorinated dibenzofurans and polychlorinated biphenyls) in Gold Rush, Black Beauty and Patty Green zucchini subspecies. We employed a model-based quantum-chemical approach and Linear Multiple Regression Analysis to correlate local atomic reactivity indices with accumulation capacities. We found several statistically significant relationships involving local reactivity indices, namely total and local atomic superdelocalizabilities, Fukui indices and net charges. This study, contrary to statistically-backed ones, is able to provide a microscopic insight of the mechanisms involved in the uptake process.
\end{abstract}

Keywords: Persistent organic pollutants, QSAR, SAR, reactivity indices, ZINDO/1, pumpkin species, zucchini species.

\section{INTRODUCTION.}

Persistent organic pollutants (POPs) are a group of man-made chemical substances that persist in the environment, bioaccumulate through the food chain, and pose a risk to human health and the environment. These chemicals come from pesticides and other industrial chemicals, and are the unwanted byproducts of industrial processes or combustion. There is conclusive evidence of long-range transport of these substances to regions where they have never been used or produced. Most POPs share characteristics such as low water solubility (they do not easily dissolve in water), the ability to accumulate in fat (high lipophilicity), and resistance to biodegradation (they take a very long time to break down). POPs include compounds such as pesticides like DDT and pollutants like polychlorinated biphenyls (PCBs). The concern over POPs' wide geographical and biological reach inspired The Stockholm Convention, ratified on May 172004 by 150 countries that focused on the elimination or reduction of twelve POPs named the Dirty Dozen. Included in this infamous group are dioxins and PCBs.

One way to cope with this problem is through phytoremediation, that is, the use of vegetation to remediate soils and sediments contaminated with organic chemicals or heavy metals. Phytoremediation can be used to clean up metals, pesticides, solvents, explosives, crude oil and polyaromatic hydrocarbons. One of the mechanisms of phytoremediation is the movement of chemicals into plants where they could be degraded, volatilized, or sequestered in plant tissues. Recent studies have shown that certain plant species, such as pumpkin and zucchini (both Cucurbita pepo L.), accumulate significant quantities of POPs. The mechanisms of the process are still not well understood ${ }^{1}$.

The systematic theoretical study of the properties of POPs began during the 1980 decade when Oliver studied the uptake of 13 chloro- and bromobenzenes and 9 other chlorinated hydrocarbons by Salmo gairdneri from water, finding that the bioconcentration factors (the concentration of a particular chemical in a biological tissue per concentration of that chemical in water surrounding that tissue) correlate well with the octanol/water partition coefficients and parachors $^{2}$. In 1987 Deneer et al. determined the acute toxicity and BCF of a series of nitrobenzene derivatives for the guppy ${ }^{3}$. Toxicity is found to be determined by both hydrophobicity (BCF, expressed by the n-octanol/water partition coefficient) and rate of reduction of the nitro group (expressed by either electrochemical half wave reduction potential or Hammett $\sigma$ values).

The study of structure-activity relationships involving bioconcentration factors is an active research line. For example, de Melo developed a quantitative structure-property relationship for predicting the logarithm of $\mathrm{BCF}$ of polychlorinated biphenyls in fishes using E-state index and topological descriptors ${ }^{4}$. His results show that the best model presented five descriptors (one E-state index and four topological descriptors) and a high quality for fit, internal, and external predictions. Peng et al. modeled the BCF of nonionic compounds using Gaussian processes and theoretical descriptors derived from electrostatic potentials on molecular surface ${ }^{5}$. They found that quantities derived from electrostatic potential, together with the molecular volume, dipole moment and the energy level of highest occupied molecular orbital can be well used to express the quantitative structure-property relationship of this sample set. Qin et al. developed five-variable model for the BCFs of nonpolar organic compounds (NPOCs) by using molecular electronegativity distance vector to characterize the structures of NPOCs and variable selection and modeling based on prediction to select the optimum descriptors ${ }^{6}$. The results show that the main structural factors influencing the BCFs of NPOCs are $-\mathrm{cCc}, \mathrm{cCcc},-\mathrm{Cl}$, and $-\mathrm{Br}$ (where "-" refers to a single bond and "c" refers to a conjugated bond). Katritzky et al. modeled the BCFs of 57 polychlorinated biphenyl congeners by quantitative structure-activity relationship based on 486 constitutional, topological, geometrical, electrostatic, quantum chemical and thermodynamic descriptors derived solely from molecular structure and calculated using CODESSA Pro (COmprehensive DEscriptors for Structural and Statistical Analysis) software ${ }^{7}$. Liu et al. employed molecular electronegativity distance vector (MEDV) derived directly from the molecular topological structures to describe the structures of 122 nonionic organic compounds (NOCs) and a quantitative relationship between the MEDV descriptors and the BCF of NOCs in fish was developed using the variable selection and modeling based on prediction (VSMP) ${ }^{8}$. Feng et al. estimated and predicted the BCF of nonionic organic chemicals in fish by electrotopological state indices and structural parameters 9 . Ivanciuc et al. made use of the biphenyl substitution-reaction network for the sequential substitution of $\mathrm{H}$-atoms by $\mathrm{Cl}$-atoms to predict the bioconcentration and bioaccumulation (BAF, the biological sequestering of a substance at a higher concentration than that at which it occurs in the surrounding environment or medium. U.S. Geological Survey, 2007) factors for $\mathrm{PCBs}^{10}$. They found that the splinoid QSSAR are better than models computed with the cluster expansion. Khadikar et al. investigated the relative potential of the PI index by comparing the results obtained using this index with those obtained with Wiener and Szeged indices ${ }^{11}$. They attempted to model hydrophobicity/lipophilicity ( $\log$ P) of the polyhalogenated biphenyls using these indices. It was observed that these distance-based topological indices gave better results for modeling $\log$ BCF than log P. Gramatica and Papa modeled log BCF of 238 non-ionic organic compounds by multiple linear regression models, using theoretical structural descriptors ${ }^{12}$. The comparison of the resulting models and $\log \mathrm{K}_{\mathrm{ow}}$ or molecular connectivity based models reveals that their approach is more predictive than the $\log \mathrm{K}$-based model. Tao et al. studied the quantitative structure-activity relationship between the $\mathrm{BCF}$ and fragment constant of organic chemicals using a database containing 337 experimental $\mathrm{BCF}$ values $^{13}$. They derived a final linear multivariate regression model that was able to account for as much as $98.0 \%$ of the variation in the experimental BCF values.

Regarding the partition coefficients of POPs, a quantitative structure property relationship model for predicting the soil-water partition coefficient of 16 polychlorinated biphenyls was developed by Jiao ${ }^{14}$. The structure of the investigated PCBs is encoded by five quantum structural descriptors and one topological index. The same author derived a quantitative structure-property relationship model for predicting the n-octanol/water partition coefficient of 21 polychlorinated biphenyls ${ }^{15}$. Yang et al. studied the aqueous solubility $\left(-\log \mathrm{S}_{\mathrm{w}}\right)$ and n-octanol/water partition coefficients $\left(\log \mathrm{K}_{\mathrm{ow}}\right)$ of polychlorinated dibenzop-dioxins ${ }^{16}$. The regression model obtained to predict $-\log \mathrm{Sw}$ contains only one variable: the mean molecular polarizability. Jäntschi et al. developed a 
genetic algorithm in order to select pairs of proper structural descriptors able to estimate and predict octanol-water partition coefficients of 206 polychlorinated biphenyls ${ }^{17}$. Other properties, such as depuration rates and toxicity have been also the subject of several QSAR analysis ${ }^{18-23}$.

Recently, Inui et al. ${ }^{24}$ studied the differential uptake of a group of polychlorinated dibenzo-p-dioxins (PCDDs), polychlorinated dibenzofurans (PCDFs), and dioxin-like polychlorinated biphenyls (PCBs) by zucchini (Cucurbita pepo) subspecies. They reported their results as Bioconcentration Factors (BCFs) calculated as the concentration of each compound in plants divided by its concentration in soil. They found that the subspecies Gold Rush (C. pepo subsp. pepo, USA) and Black Beauty (C. pepo subsp. pepo, Japan) were better accumulators than Patty Green subspecies (C. pepo subsp. texana). Given the magnitude of the contamination problem, the analysis of the mechanism or mechanisms used by plants to accumulate pollutant agents seems to be a necessary task. Bordás et al. ${ }^{25}$, used statistical analysis and 1,821 chemical descriptors (a molecular descriptor is a mathematical value that describes the structure or shape of a molecule), to analyze the BCF data of Inui et al. They found several statistically-backed equations mixing molecular descriptors obtained from classical chemistry with others resulting from quantum-chemical calculations. This kind of procedure, in which statistics plays a central role but no physics is involved, works nicely sometimes but is not able to provide feedback for a theoretical understanding of the problem ${ }^{26}$. A totally different approach is the creation of an ideal model of the biological system and the process under study ${ }^{26}$. The assumptions of the model are translated into algebraic statements, deriving naturally one or more equations showing the expected relationships. In our Laboratory we have generated model-based equations for equilibrium constants. This line of thought started with the work of Agin et al. during the $1960 \mathrm{~s}^{27}$, was continued by Cammarata ${ }^{28}$, crystallized in the work of Peradejordi ${ }^{29}$ and was extended by one of $\mathrm{us}^{30-32}$. Its application to the analysis of experimental data on drug-receptor interactions showed ${ }^{33-37}$, beyond all reasonable doubt, that it has predictive capacity ${ }^{38}$ and is even able to detect erroneous experimental data ${ }^{39}$. On the other hand, the lipophilic properties of molecules govern the penetrability of biological membranes and the partition between organic and aqueous phases. Lipophilicity is generally represented by the partition coefficient, $\log \mathrm{P}^{40}$. As Cammarata et al. showed that $\log \mathrm{P}$ can be expressed as function of the same reactivity indices than the above mentioned model describing equilibrium constants ${ }^{41-43}$, we dispose of a tool useful for both purposes.

Here we report the results of a search of formal relationships between Inui's accumulation data of some pollutant molecules in three zucchini subspecies and the electronic-molecular structure of the former.

\section{Materials and Methods.}

It seems necessary first to comment on the $\mathrm{BCF}$ data. The set of compounds includes polychlorinated dibenzo-p-dioxins (PCDDs), polychlorinated dibenzofurans (PCDFs) and polychlorinated biphenyls (PCBs), all depicted in Fig. 1. The dioxin-contaminated soil was collected from the surroundings of an incinerator and homogenized. It is reasonable therefore to accept that the pollutants are well distributed inside the soil. Four or five one-week-old zucchini seedlings were cultivated for 32 days in that soil and, at the end of the process; the aerial parts were sampled for the extraction and quantification of the pollutants. We may note at least that the number of plants used is not sufficiently large in our opinion, and that we do not know for example if the average total root area in contact with the soil and the average cross-section of the roots and stem are similar for all subspecies employed.

The steps for the accumulation process of hydrophobic compounds in plants are six: exudation of compounds from the roots, desorption from soil organic matter and solubilization of hydrophobic compounds by the exuded compounds, adsorption on root surfaces, translocation from the root surface to the root stele, translocation from the roots to the aerial parts and metabolism ${ }^{24,44-45}$. As we analyze the bioconcentration factors that are the final product of these six steps, in principle we have not the possibility of an a prori knowledge of the dominant step or steps. If we accept that in the case of the data of Inui et al. the soil solids, the soil solution and the root constitution are the same (i.e., more or less constant) for all the plant species studied, we may test the hypothesis that the Bioconcentration Factors are a function only of the electronic structure of the studied molecules.

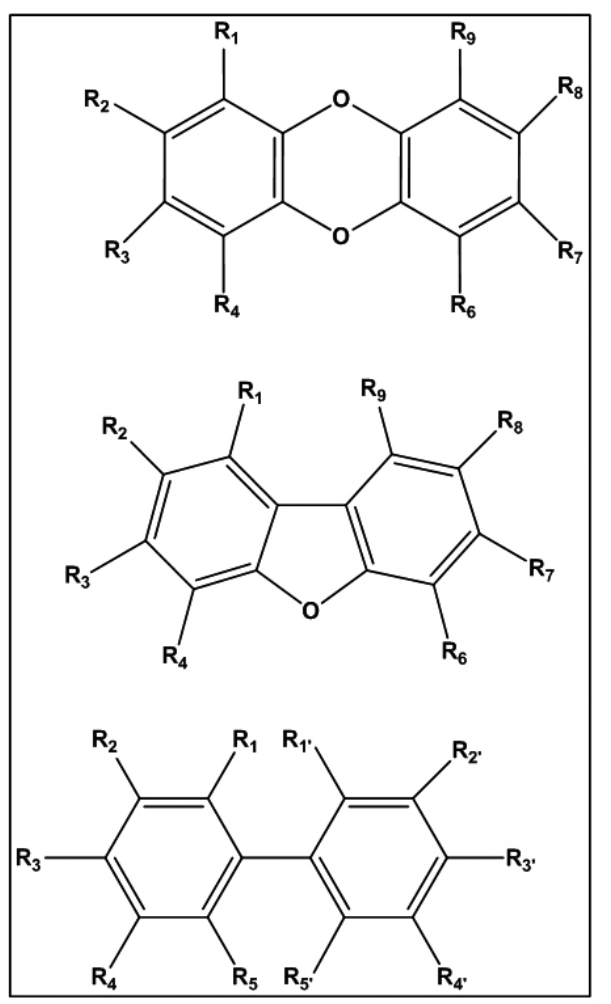

Fig. 1. From top to bottom: general structures for polychlorinated dibenzop-dioxins (PCDD, set I), dibenzofurans (PCDF, set II) and biphenyls (PCB, set III).

For this model we may then write ${ }^{31}$ :

$$
\begin{aligned}
& \quad-\log B C F=a+\sum_{i}\left[e_{i} Q_{i}+f_{i} S_{i}^{E}+s_{i} S_{i}^{N}\right]+\sum_{i} \sum_{m}\left[h_{i}(m) F_{i}^{m}+j(m) S_{i}^{E}(m)\right]+ \\
& +\sum_{i} \sum_{m^{\prime}}\left[r_{i}\left(m^{\prime}\right) F_{i}\left(m^{\prime}\right)+t_{i}\left(m^{\prime}\right) S_{i}^{N}\left(m^{\prime}\right)\right]
\end{aligned}
$$

where a and e, f, s, h, j, r and t are constants. $Q_{i}, S_{i}{ }^{N}$ and $S_{i}{ }^{E}$ are, respectively, the net charge, the total atomic nucleophilic superdelocalizability (NSD) and the total electrophilic superdelocalizability (ESD) of atom $\mathrm{i}^{45,46} \cdot \mathrm{F}_{\mathrm{i}}(\mathrm{m})$ is the Fukui index for atom $\mathrm{i}$ and $\mathrm{MO} \mathrm{m}, \mathrm{S}^{\mathrm{E}}(\mathrm{m})$ is the partial ESD of atom $\mathrm{i}$ at $\mathrm{MO}$ $\mathrm{m}$, and so on. The summation on $\mathrm{m}$ is over the occupied MOs and the one on $\mathrm{m}$ ' is over the empty ones.

Then, for $\mathrm{N}$ molecules we have a set of simultaneous equations 1 . This system of simultaneous equations holds for all the atoms of the molecule directly perturbed by their interaction with the receptor. Combined with the usual multiple-regression techniques, these equations can be usefully applied to estimate the relative variation of the Bioconcentration Factors in the group of molecules analyzed. Here statistical analysis is used, not to see whether there is a structure-activity relationship, but to find the best one. We employed the additional hypothesis stating that it is a heavy-atom skeleton, common to a family of molecules that accounts for the variation of the BCFs. The substituents influence the BCFs values through the modification of the electronic structure of the skeleton.

The calculation of the numerical values of the reactivity indices of Eq. 1 was carried out with Zerner's ZINDO/1 semiempirical method ${ }^{48,49}$. This choice is justified because after geometry optimization ZINDO/1 is the only method producing positive nucleophilic superdelocalizabilities as required by the model ${ }^{50}$. As expected, ZINDO/1 gave good results when applied to the interaction of a group of 3 -substituted morphinans with $\mu, \delta$ and $\kappa$ opioid receptors $^{51}$, and for the inhibition of wild-type and drug-resistant HIV-1 reverse transcriptase by some thiazolidenebenzenesulfonamide derivatives ${ }^{52}$. The problem of obtaining good numerical values for the NSD index with $a b$ initio and DFT calculations has not yet been solved but there are some promising 
results $^{35,53}$. We need to stress that the correct choice of more primitive methods (Extended Hückel Theory) can be very helpful in interpreting experimental results $^{54-56}$. The statistical fitting of equation 1 was performed by means of a linear Multiple Regression Analysis (MRA) with the negative logarithm of the average $\mathrm{BCF}$ values (pBCF) for Gold Rush and Black Beauty subspecies as the dependent variable and the static reactivity indices of the atoms belonging to a common skeleton as independent variables. The skeletons for sets I, II and III are depicted in Fig. 2. Hyperchem was employed for all quantum-chemical calculations $^{57}$. For linear multiple regression analysis we used Statistics software ${ }^{58}$.

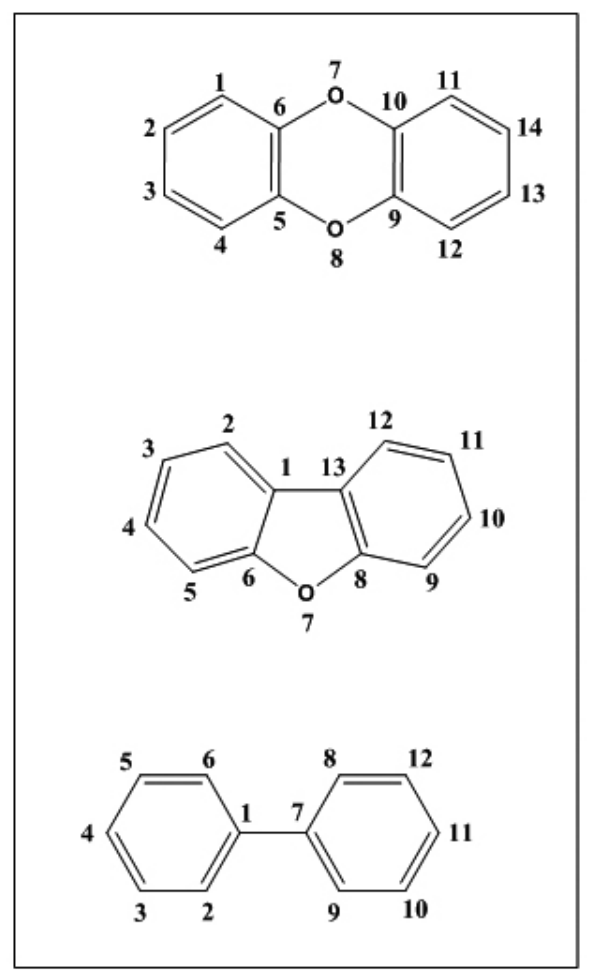

Fig. 2. From top to bottom. Common skeleton numbering for sets I-III.

\section{RESULTS AND DISCUSSION.}

Before presenting the results we must mention that the final equations correlate the variation of the $\mathrm{BCF}$ values with the variation of one or more local atomic reactivity indices. Thus, any index making a constant contribution will not appear. We analyzed the possibility of obtaining a statistically good equation for a set including all the molecules and with a skeleton constituted by the twelve carbon atoms constituting the aromatic rings common to all these molecules. The best equation had a standard error of estimate of 0.29 and therefore it was discarded.

For the group of 9 polychlorinated dioxin derivatives (set I, top of Fig. 1) the best equation is:

$$
\mathrm{pBCF}=13.55( \pm 1.32)+2.20( \pm 0.25) \mathrm{S}_{6}^{\mathrm{E}}
$$

with $n=9, R=0.96, R^{2}=0.92$, a standard error of the estimate of 0.15 , outliers $>2 \mathrm{~S}=0$ and $\mathrm{F}(1,7)=76.56(\mathrm{p}<0.00005) . \mathrm{S}_{6}^{\mathrm{E}}$ is the total atomic electrophilic superdelocalizability of atom 6 and the result of Student's t test for the significance of the coefficient of this variable is $\mathrm{t}\left[\mathrm{S}_{6}^{\mathrm{E}}\right]=8.75(\mathrm{p}<0.000051)$. Table 1 presents the observed and predicted values obtained with Eq. 2. The molecular nomenclature used here is straightforward: 368TCDD means that positions 3,6 and 8 are substituted with chlorine atoms, TC stands for trichloro and DD for dibenzodioxin. Table 1 presents the observed and predicted values and Fig. 3 the plot of predicted vs. observed values for Eq. 2 .

Eq. 2 shows that the variation of the $\mathrm{BCF}$ is related to the variation of the total atomic electrophilic superdelocalizability of atom 6 (see the top of Fig. 2). Atom 6 is interacting then with one or more unoccupied MOs located on the root wall (a region composed of, for example, atoms with positive net charges or by a cationic group). A high value of $\mathrm{S}_{6}^{\mathrm{E}}$ is needed for a good accumulation susceptibility This is consistent with the presence of a neighboring oxygen atom with a negative net charge. This process is orbital-controlled ${ }^{59}$.

Table 1. Observed and predicted values for set I (Gold Rush and Black Beauty subspecies).

\begin{tabular}{|c|c|c|}
\hline Molecule & Observed Value $^{\mathrm{a}}$ & Predicted Value $^{\mathrm{b}}$ \\
\hline $1368 \mathrm{TCDD}$ & 1.18 & 1.17 \\
\hline $1379 \mathrm{TCDD}$ & 1.50 & 1.38 \\
\hline $2378 \mathrm{TCDD}$ & 1.86 & 1.81 \\
\hline $12378 \mathrm{PCDD}$ & 1.69 & 1.90 \\
\hline $123478 \mathrm{HCDD}$ & 2.11 & 2.34 \\
\hline $123678 \mathrm{HCDD}$ & 2.03 & 2.03 \\
\hline $123789 \mathrm{HCDD}$ & 2.00 & 2.03 \\
\hline $1234678 \mathrm{HCDD}$ & 2.65 & 2.46 \\
\hline OCDD & 2.67 & 2.57 \\
\hline
\end{tabular}

a. Data from Ref. 2. b. With Eq. 2.

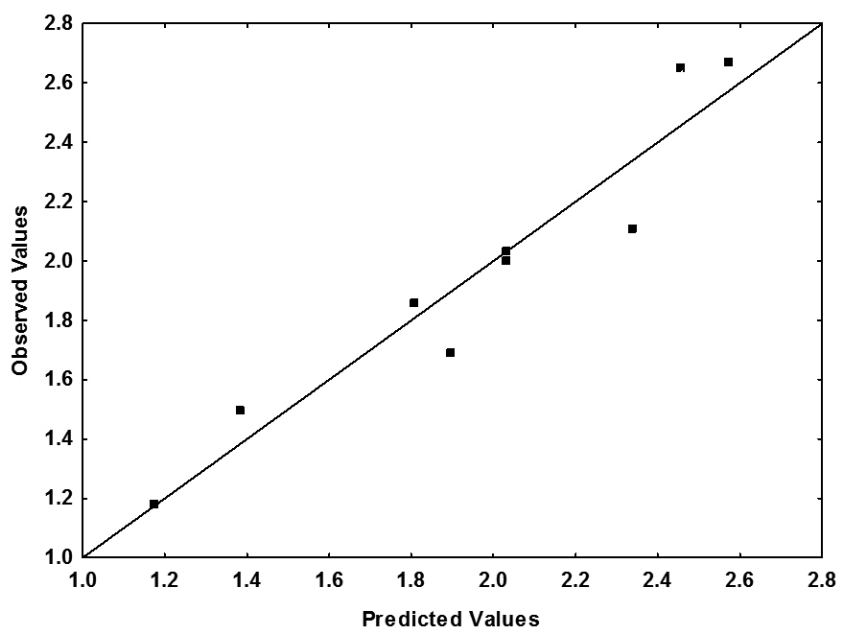

Fig. 3. Plot of predicted vs. observed values for Set I with Eq. 2 (Gold Rush and Black Beauty subspecies).

For the group of 11 polychlorinated dibenzofurans (set II, middle of Fig. 1) the best equation is:

$$
\mathrm{pBCF}=-8.81( \pm 1.16)+0.93( \pm 0.10) \mathrm{S}_{8}^{\mathrm{N}}
$$

with $\mathrm{n}=11, \mathrm{R}=0.95, \mathrm{R}^{2}=0.91$, a standard error of the estimate of 0.20 , outliers $>2 \mathrm{~S}=0$ and $\mathrm{F}(1,9)=93.11 \quad(\mathrm{p}<0.000001) . \mathrm{S}_{8} \mathrm{~N}$ is the total atomic nucleophilic superdelocalizability of atom 8 . The result of Student's $t$ test for the significance of the coefficient of this variable is $\mathrm{t}\left[\mathrm{S}_{8} \mathrm{~N}\right]=9.65(\mathrm{p}<0.000005)$. Table 2 presents the observed and predicted values obtained and Fig. 5 shows the plot of predicted vs. observed values.

In this case the variation of the $\mathrm{BCF}$ is related only to the variation of the total NSD of atom 8 . The empty MOs located on this atom interact with the occupied MOs of a site located in the plant. Eq. 3 shows that a high accumulation susceptibility is associated with a high value of the total atomic nucleophilic superdelocalizability (which is always positive) of atom 8 (see middle of Fig. 2). High values for NSD are obtained with high values of the Fukui indices and low eigenvalues for the first empty MOs located on atom 8. This process is also orbital-controlled. 
Table 2. Observed and predicted values for Set II (Gold Rush and Black Beauty subspecies).

\begin{tabular}{|c|c|c|}
\hline Molecule & Observed Value $^{a}$ & Predicted Value ${ }^{\mathrm{b}}$ \\
\hline 1. $1278 \mathrm{TCDF}$ & 1.85 & 1.49 \\
\hline 1. $2378 \mathrm{TCDF}$ & 1.40 & 1.55 \\
\hline 3. $12378 \mathrm{PCDF}$ & 1.73 & 1.79 \\
\hline 4. $23478 \mathrm{PCDF}$ & 1.82 & 1.89 \\
\hline 5. $123478 \mathrm{HCDF}$ & 2.19 & 2.13 \\
\hline 6. $123678 \mathrm{HCDF}$ & 2.19 & 2.42 \\
\hline 7. $123789 \mathrm{HCDF}$ & 2.66 & 2.46 \\
\hline 8. $234678 \mathrm{HCDF}$ & 2.26 & 2.53 \\
\hline 9. $1234678 \mathrm{HCDF}$ & 2.69 & 2.79 \\
\hline 10. $1234789 \mathrm{HCDF}$ & 3.00 & 2.83 \\
\hline 11. OCDF & 3.68 & 3.57 \\
\hline
\end{tabular}

a. Data from Ref. 2. b. With Eq. 3.

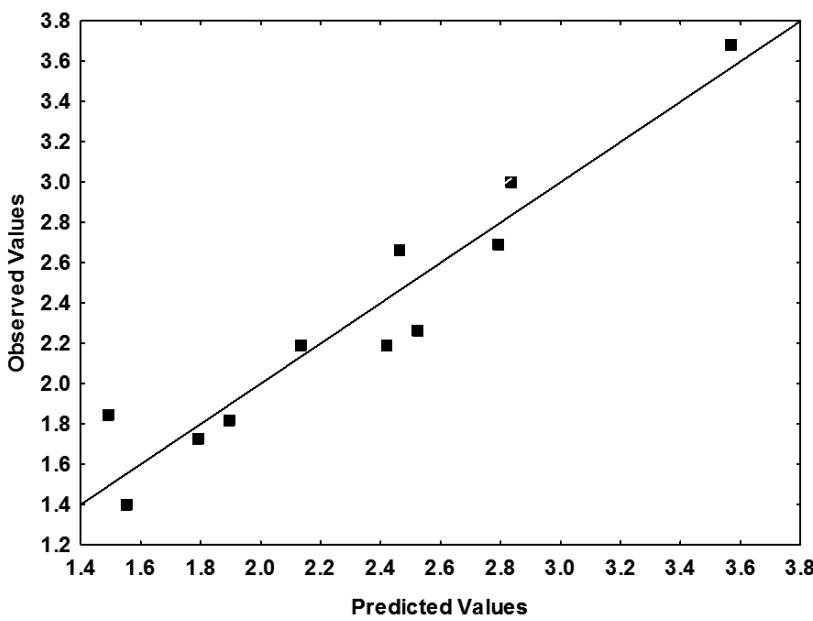

Fig. 4. Plot of predicted vs. observed values for Set II with Eq. 3 (Gold Rush and Black Beauty subspecies).

For the group of 14 polychlorinated biphenyls (set III, bottom of Fig. 1) the best equation is:

$\mathrm{pBCF}=3.52( \pm 0.04)-18.43( \pm 3.13) \mathrm{F}_{6}(\mathrm{HOMO})+2.49( \pm 0.62) \mathrm{F}_{2}(\mathrm{HOMO}-2)-$ $-2.98( \pm 0.75) \mathrm{S}_{2}^{\mathrm{E}}(\mathrm{HOMO}-1)$

with $n=14, R=0.94, R^{2}=0.88$ a standard error of the estimate of 0.15 , outliers $>2 S=0$ and $F(3,10)=24.36(p<0.00006)$. The results of Student's t-test for the significance of the coefficients of the variables are: $t\left[\mathrm{~F}_{6}(\mathrm{HOMO})\right]=$ $-5.89(\mathrm{p}<0.002), \mathrm{t}[\mathrm{F}(\mathrm{HOMO}-2)]=4.03(\mathrm{p}<0.002)$ and $\mathrm{t}\left[\mathrm{S}^{\mathrm{E}}(\mathrm{HOMO}-1)\right]=-3.99$ $(\mathrm{p}<0.003) . \mathrm{F}_{6}(\mathrm{HOMO})$ is the Fukui index of atom 6 at the HOMO, $\mathrm{F}_{2}(\mathrm{HOMO}-2)$ is the Fukui index of atom 2 at the third occupied $\mathrm{MO}$ and $\mathrm{S}_{2}{ }^{\mathrm{E}}(\mathrm{HOMO}-1)$ is the orbital electrophilic superdelocalizability of atom 1 at the second occupied MO. The squares of the partial correlation coefficients are: $\mathrm{r}^{2}\left[\mathrm{~S}^{\mathrm{E}}(\mathrm{HOMO}-1)-\right.$ $\left.\mathrm{F}_{6}(\mathrm{HOMO})\right]=0.26, \mathrm{r}^{2}\left[\mathrm{~S}_{2}{ }^{\mathrm{E}}(\mathrm{HOMO}-1)-\mathrm{F}_{2}(\mathrm{HOMO}-2)\right]=0.25$ and $\mathrm{r}^{2}\left[\mathrm{~F}_{6}(\mathrm{HOMO})-\right.$ $\left.\mathrm{F}_{2}(\mathrm{HOMO}-2)\right]=0.08$. Table 3 presents the observed and predicted values and Fig. 5 the plot of predicted vs. observed values for Eq. 4 .

The variation of the $\mathrm{BCF}$ values is associated to the simultaneous variation of three local atomic reactivity indices. Before presenting an analysis we must stress that in the case of PCBs the two phenyl rings are not coplanar. Therefore, for example, positions $\mathrm{R}_{1}$ and $\mathrm{R}_{1}$, are not fully equivalent. In this case we have a temperature and medium-dependent population of rotamers. It has been suggested that the variable uptake of these molecules occurs principally as a result of steric effects relating to the orientation of the two phenyl rings and the chlorine substitution patterns ${ }^{35}$.

This interaction is also orbital-controlled. In the case we could analyze by separate the contribution of each local atomic reactivity index (this is not fully correct) we can say that a good whole accumulation susceptibility is associated with a high value of the Fukui index for the HOMO at atom 6 and with low values for the Fukui index for the HOMO-1 (the occupied MO lying below the HOMO) at atom 2 and for the local atomic orbital electrophilic superdelocalizability of HOMO-2 (the occupied MO lying below the HOMO1) at atom 2 (see the lower part of Fig. 2). Therefore, atom 6 seems to interact with one or more empty MOs located on a site of the root. Atom 2 should make a low but non zero contribution to the upper occupied MOs (the contribution of atom 2 to HOMO is close to zero). We may interpret this as the interaction of atom 2 with an electron-poor area located in a region which imposes a limit on charge transfer. Therefore, the accumulation of PCBs seems to depend on their weak interaction with two separate but closely located areas having different electron accepting capacities.

Table 3. Observed and predicted values for set III (Gold Rush and Black Beauty subspecies).

\begin{tabular}{|c|c|c|}
\hline Molecule & Observed Value ${ }^{a}$ & Predicted Value ${ }^{\mathrm{b}}$ \\
\hline 1. $33^{\prime} 44^{\prime}-\mathrm{TCB}$ & 1.87 & 1.82 \\
\hline 2. $344^{\prime} 5-\mathrm{TCB}$ & 1.81 & 1.62 \\
\hline 3. $33^{\prime} 44^{\prime} 5-\mathrm{PCB}$ & 1.65 & 1.83 \\
\hline 4. $33^{\prime} 44^{\prime} 55^{\prime}-\mathrm{HCB}$ & 2.10 & 2.08 \\
\hline 5. $233^{\prime} 44^{\prime}-\mathrm{PCB}$ & 0.98 & 1.02 \\
\hline 6. $2344^{\prime} 5-\mathrm{PCB}$ & 1.14 & 1.20 \\
\hline 7. $23^{\prime} 44^{\prime} 5-\mathrm{PCB}$ & 0.92 & 1.20 \\
\hline 8. 2’344’5-PCB & 1.05 & 1.11 \\
\hline 9. $233^{\prime} 44^{\prime} 5-\mathrm{HCB}$ & 1.32 & 1.26 \\
\hline 10. $233^{\prime} 44^{\prime} 5^{\prime}-\mathrm{HCB}$ & 1.32 & 1.19 \\
\hline 11. $23^{\prime} 44^{\prime} 55-\mathrm{HCB}$ & 1.75 & 1.72 \\
\hline 12. $233^{\prime} 44^{\prime} 55-\mathrm{HCB}$ & 1.96 & 2.08 \\
\hline 13. $22{ }^{\prime} 33^{\prime} " 44^{\prime} 5-\mathrm{HCB}$ & 1.58 & 1.41 \\
\hline 14. $22^{\prime} 344^{\prime} 55^{\prime}-\mathrm{HCB}$ & 1.53 & 1.46 \\
\hline
\end{tabular}

a. Data from Ref. 2. b. With Eq. 4.

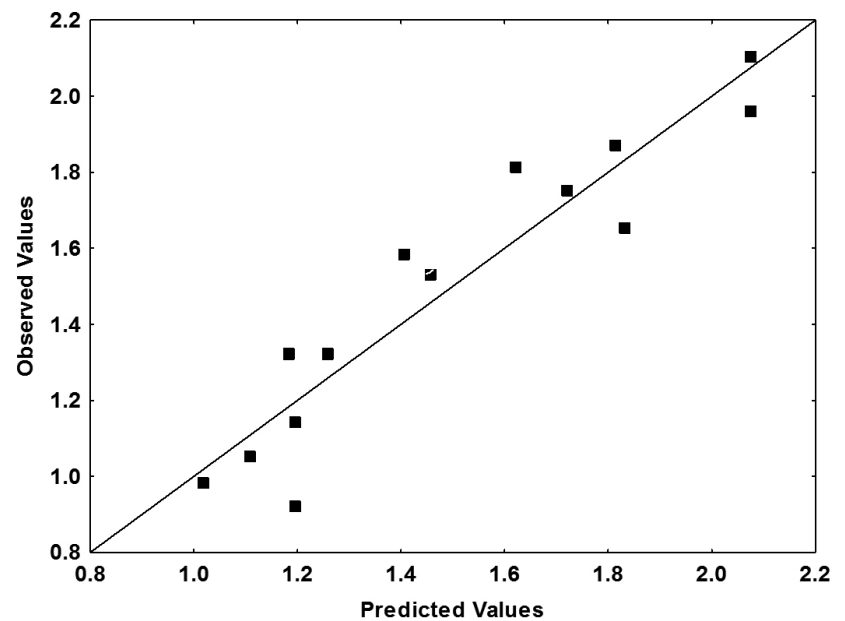

Figure 5. Plot of predicted vs. observed values for Set III with Eq. 4 (Gold Rush and Black Beauty subspecies).

An interesting question, not addressed by Bordás et al., is why the Patty Green subspecies is a bad accumulator. To analyze this fact we have carried out a similar MRA analysis but with the negative logarithm of Patty Green BCF values as the dependent variable. The best equation obtained for set I (PCDDs, 
Patty Green) is

$$
\mathrm{pBCF}=-2.24( \pm 0.71)+0.45( \pm 0.05) \mathrm{S}_{3}^{\mathrm{N}}
$$

with $\mathrm{n}=10, \mathrm{R}=0.96, \mathrm{R}^{2}=0.92$, a standard error of the estimate of 0.16 , outliers $>2 \mathrm{~S}=0$ and $\mathrm{F}(1,7)=76.29 \quad(\mathrm{p}<0.00005) . \quad \mathrm{S}_{3}{ }^{\mathrm{N}}$ is the total atomic nucleophilic superdelocalizability of atom 3 . The result of Student's $t$ test for the significance of the coefficient of this variable is $\mathrm{t}\left[\mathrm{S}_{3}{ }^{\mathrm{N}}\right]=8.73(\mathrm{p}<0.000052)$. Table 4 presents the observed and predicted values obtained and Fig. 6 shows the plot of predicted vs. observed values for Eq. 5 .

Regarding the Patty Green results for PCDDs, we note that the condition imposed by Eq. 5 is a high value for the total NSD of atom 3. This suggests that occupied MOs located on atom 3 are interacting with one or more unoccupied MOs located on the plant, a fact that is not contradictory with the conditions imposed by Eq. 3 to the Gold Rush and Black Beauty subspecies

Table 4. Observed and predicted values for set I (PCDDs, Patty Green subspecies).

\begin{tabular}{|c|c|c|}
\hline Molecule & Observed Value $^{\mathrm{a}}$ & Predicted Value $^{\mathrm{b}}$ \\
\hline 1 & 3.23 & 3.12 \\
\hline 2 & 3.54 & 3.53 \\
\hline 3 & 3.41 & 3.52 \\
\hline 4 & 3.81 & 3.95 \\
\hline 5 & 4.50 & 4.37 \\
\hline 6 & 3.99 & 4.07 \\
\hline 7 & 4.06 & 4.06 \\
\hline 8 & 4.75 & 4.49 \\
\hline 9 & 4.40 & 4.62 \\
\hline
\end{tabular}

a. Data from Ref. 24 b. With Eq. 5 .

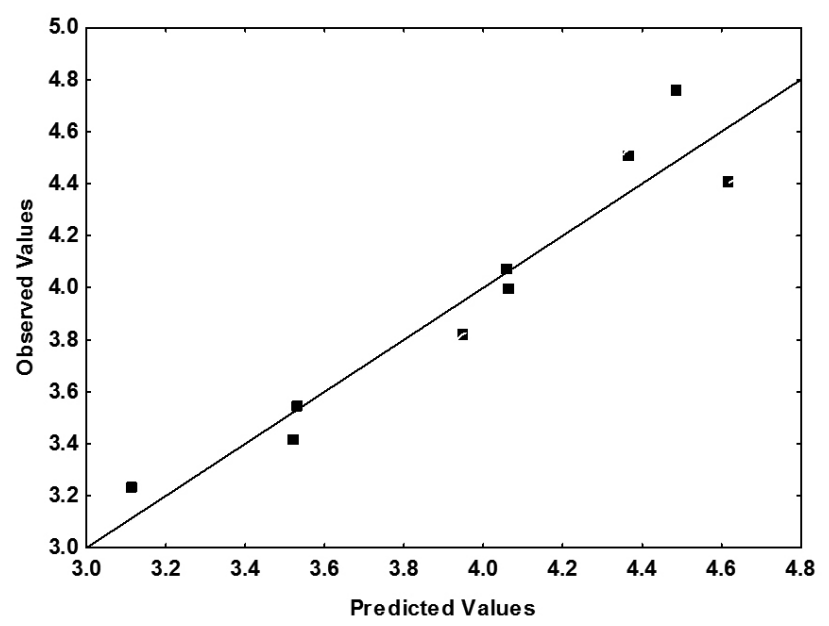

Figure 6. Plot of predicted vs. observed values for Eq. 5 (Patty Green subspecies).

The best equation for set II (PCDFs, Patty Green) is:

$$
\mathrm{pBCF}=-6.81( \pm 1.11)+0.95( \pm 0.09) \mathrm{S}_{8}^{\mathrm{N}}
$$

with $\mathrm{n}=11, \mathrm{R}=0.96, \mathrm{R}^{2}=0.92$, a standard error of the estimate of 0.20 , outliers $>2 \mathrm{~S}=0$ and $\mathrm{F}(1,9)=104.73(\mathrm{p}<0.000001) . \mathrm{S}_{\mathrm{s}}^{\mathrm{N}}$ is the total atomic nucleophilic superdelocalizability of atom 8 The result of Student's t test for the significance of the coefficient of this variable is $\mathrm{t}\left[\mathrm{S}_{8}^{\mathrm{N}}\right]=9.65(\mathrm{p}<0.000005)$. Table 5 presents the observed and predicted values and Fig. 7 shows the plot of predicted vs. observed values for Eq. 6. Notice that Eq. 6 is almost identical to Eq. 3. We shall discuss this finding below.
Table 5. Observed and predicted values for set II (PCDFs, Patty Green subspecies).

\begin{tabular}{|c|c|c|}
\hline Molecule & Observed Value $^{\mathrm{a}}$ & Predicted Value $^{\mathrm{b}}$ \\
\hline 1 & 4.05 & 3.71 \\
\hline 2 & 3.39 & 3.77 \\
\hline 3 & 3.97 & 4.01 \\
\hline 4 & 4.20 & 4.12 \\
\hline 5 & 4.25 & 4.36 \\
\hline 6 & 4.54 & 4.66 \\
\hline 7 & 4.82 & 4.70 \\
\hline 8 & 4.79 & 4.76 \\
\hline 9 & 5.10 & 5.038 \\
\hline 10 & 5.22 & 5.077 \\
\hline 11 & 5.72 & 5.83 \\
\hline
\end{tabular}

a. Data from Ref. 24 b. With Eq. 6.

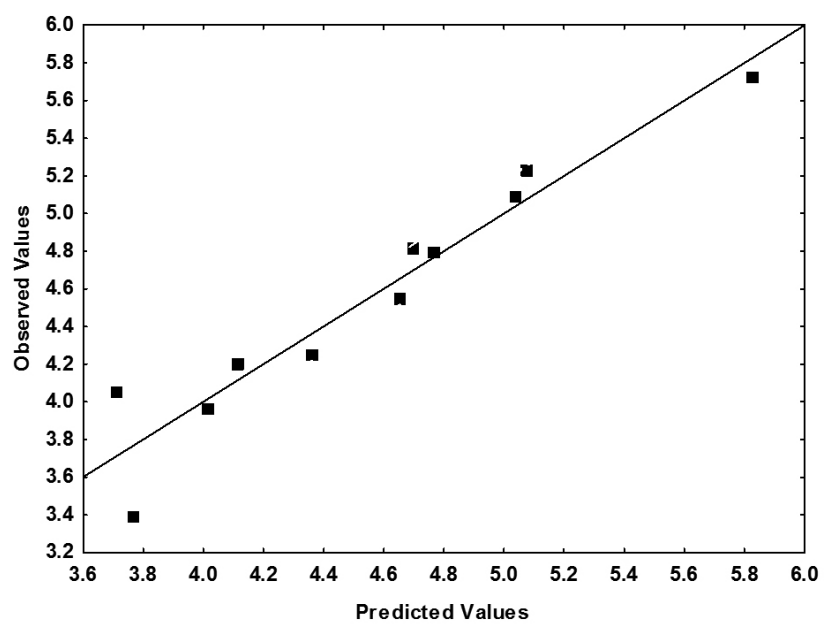

Figure 7. Plot of predicted vs. observed values for Eq. 6 (Patty Green subspecies).

The best equation for set III (PCBs, Patty Green ) is:

$$
\mathrm{pBCF}=35.89( \pm 3.82)+5.09( \pm 0.65) \mathrm{S}_{6}^{\mathrm{E}}-15.03( \pm 2.12) \mathrm{Q}_{10}
$$

with $n=14, R=0.95, R^{2}=0.90$, a standard error of the estimate of 0.26 , outliers $>2 \mathrm{~S}=0$ and $\mathrm{F}(2,11)=48.02 \quad(\mathrm{p}<0.000001) . \quad \mathrm{S}_{6}^{\mathrm{E}}$ is the total atomic electrophilic superdelocalizability of atom 6 and $Q_{10}$ is the net charge of atom 10. The result of Student's t test for the significance of the coefficient of this variable are $\mathrm{t}\left[\mathrm{S}_{6}{ }^{\mathrm{E}}\right]=7.88 \quad(\mathrm{p}<0.000008)$ and $\mathrm{t}\left[\mathrm{Q}_{10}\right]=-7.10 \quad(\mathrm{p}<0.00002)$. The square of the partial correlation coefficient is $\mathrm{r}^{2}\left[\mathrm{~S}_{6}^{\mathrm{E}}-\mathrm{Q}_{10}\right]=0.17$. Table 6 presents the observed and predicted values and Fig. 8 shows the plot of predicted vs. observed values for Eq. 7 .

Eq. 7 tells us that, in the Patty Green subspecies case, occupied MOs located on atom 6 are interacting with one or more unoccupied MOs of a site in the plant. Atom 10 should have a positive, possibly small, net charge. The former condition is fully compatible with Eq. 4 for the Gold Rush and Black Beauty subspecies.

The comparison of Eq. 2 and 3 shows that PCDD and PCDF compounds have opposite conditions for a carbon atom close to the oxygen atom: in one case the carbon atom should have an electron donor capacity (PCDD) and in the other the carbon atom should have an electron acceptor capacity (PCDF). In the case of PCBs (Eq. 4), one of the two carbon atoms involved in the interaction should have an electron donor capacity while the other carbon atom should have an electron acceptor capacity. Noting that these two atoms belong to the same ring it could be that they share the same interaction sites for PCDDs and PCDFs. 
Table 6. Observed and predicted values for set III (PCBs, Patty Green subspecies).

\begin{tabular}{|c|c|c|}
\hline & Observed Value $^{\mathrm{a}}$ & Predicted Value $^{\mathrm{b}}$ \\
\hline 1 & 2.53 & 2.59 \\
\hline 2 & 3.05 & 2.67 \\
\hline 3 & 4.22 & 3.79 \\
\hline 4 & 4.87 & 4.65 \\
\hline 5 & 2.73 & 2.91 \\
\hline 6 & 3.10 & 2.93 \\
\hline 7 & 2.71 & 2.95 \\
\hline 8 & 2.87 & 2.95 \\
\hline 9 & 3.75 & 4.01 \\
\hline 10 & 3.77 & 3.77 \\
\hline 11 & 3.83 & 3.82 \\
\hline 12 & 4.66 & 4.65 \\
\hline 13 & 4.21 & 4.18 \\
\hline 14 & 3.56 & 3.98 \\
\hline
\end{tabular}

a. Data from Ref. 24. b. With Eq. 7.

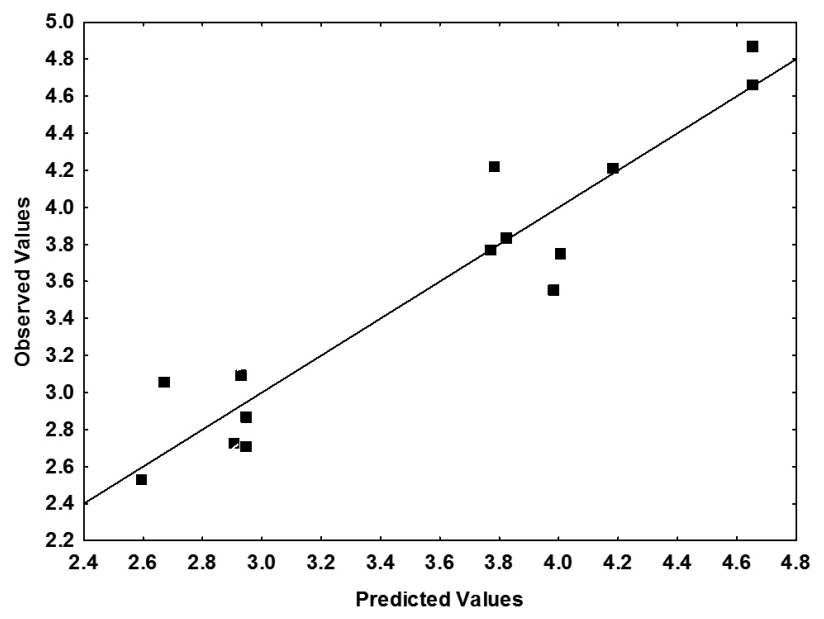

Figure 8. Plot of predicted vs. observed values for Eq. 7 (Patty Green subspecies).

In a recent paper of Inui et al., Patty Green and Gold Rush species were grown hydroponically ${ }^{45}$. Inui at al. find four interesting facts. 1 . The concentration of PCDDs, PDCFs and PCBs in the aerial parts are greater in Gold Rush that in Patty Green, supporting earlier results ${ }^{24} .2$. The BCFs (calculated here by dividing the concentration in the aerial parts by the initial concentration in the nutrient solution) are greater for Gold Rush than for Patty Green. 3. The root concentration factors ( $\mathrm{RCFs}$, calculated by dividing the concentrations of POPs in the roots by their initial concentration in the nutrient solution) are almost the same in Patty Green and Gold Rush. 4. The translocation factors (TFs, calculated by dividing the concentrations of PCDDs, PCDFs and PCBs in the aerial parts by those in the roots) are higher for Gold Rush that in Patty Green $^{45}$.

A very interesting fact is that the equation for the BCF factors of PCDFs in Patty Green subspecies (Eq. 6), a bad accumulator, is identical to Eq. 3 which holds for good accumulators (Gold Rush and Black Beauty subspecies). This identity implies that after the translocation step a factor of unknown nature is affecting the accumulation of PCDFs in Patty Green subspecies.

On the other hand, Eq. 2 (BCFs for PCDDS in Gold Rush and Black Beauty subspecies) and Eq. 5 (Patty Green subspecies) show opposite donor-acceptor properties. Nevertheless, and within in alternant/nonalternant description of the common skeleton, atoms 3 and 6 of PCDDs should have different electronic properties. Moreover, equation 4 for the PCBs of Gold Rush and Black Beauty subspecies and equation 7 for Patty Green subspecies contain the same kind of local atomic reactivity indices for atom 6 . Therefore it seems that at the level of the translocation step there is no a reason explaining the bad accumulator capacity of Patty Green subspecies.

Here we suggest, as a tentative explanation, that in the Patty Green subspecies the structure of the after-translocation pathway leading to the aerial parts of the plant is somewhat different in comparison with the Gold Rush and Black Beauty subspecies. This structural difference could, for example, diminish the traveling velocity of the POPs toward the plant's upper parts. Another possibility is that the accumulation volume in the aerial parts of Patty Green is smaller than the equivalent area in the other two subspecies. Only future experimental work by plant physiologists will elucidate this point (see also Refs. 60 and 61).

\section{CONCLUSIONS}

The main conclusion of this work is that we were able to find formal relationships between the electronic structure of some pollutants and their accumulation in three zucchini subspecies. Equations 2 to 7 are statistically significant and that, in the case of Eqs. 4 and 7, all variables appearing inside them are also significant and not correlated. Therefore, there is a direct dependence between the variation of the bioconcentration factors and the variation of one or more local reactivity indices of the POPs studied here. This result is very satisfactory when one analyzes the number of approximations used for the generation of the model.

The similarity between the results for the Gold Rush and Black Beauty subspecies and the ones for the Patty Green subspecies suggests that the bad accumulation properties of the latter seem to depend on the characteristics of the after-translocation milieu.

This model-based study, contrarily to the statistically-backed ones, is able to provide a microscopic insight of the mechanisms involved in the uptake process. It also sheds light on possible physical differences between subspecies that had not been noted previously.

\section{REFERENCES}

1. M.P.N. Gent, J.C. White, Z.D. Parrish, M. Isleyen, B.D. Eitzer, M.J. Incorvia, Environ. Toxicol. Chem. 26, 2467 (2007).

2. B.G. Oliver, Proc. Workshop, Hamilton, Ontario, pp. 301-317, 1983.

3. J.W. Deneer, T. L. Sinnige, W. Seinen, J.L.M. Hermens, Aquatic Toxicol. 10, 115 (1987).

4. E.B. de Melo, Ecotoxicol. Environ. Saf. 75, 213 (2012)

5. S. Peng, Z Jian-Wei, Z. Peng, X. Lin, Chemosphere 83, 1045 (2011).

6. L.T. Qin, S.S. Liu, H.L. Liu, Mol. Diversity 14, 67 (2010).

7. A.R. Katritzky, S.H. Slavov, I.B. Stoyanova-Slavova, M. Karelson, Toxicol. Environ. Chem. 92, 1233 (2010).

8. S.S. Liu, L.T. Qin, H.L: Liu, D.Q. Yin, J. Mol. Mod. 14, 83 (2008)

9. C.J. Feng, W.H. Yang, L.L. Mu, Jiegou Huaxue, 27, 575 (2008).

10. T. Ivanciuc, O. Ivanciuc, D.J. Klein, Mol. Diversity, 10, 133 (2006).

11. P.V. Khadikar, S. Singh, D. Mandloi, S. Joshi, A.V. Bajaj, Bioorg. Med. Chem., 11, 5045 (2003).

12. P. Gramatica, E. Papa, QSAR Comb. Sci., 22, 374 (2003).

13. S. Tao, H. Hu, X. Lu, R.W. Dawson, F. Xu, J. Environ. Sci. Health, B36, $631(2001)$

14. L. Jiao, 2011 SSITE International Conference on Future Material Research and Industry Application, FMRIA, Macau. 455-456, 930 (2012).

15. L. Jiao, 2011 SSITE International Conference on Future Material Research and Industry Application, Macau. 455-456, 925 (2012).

16. G.Y. Yang, J. Yu, Z.Y. Wang, X.L. Zeng, X.H. Ju, QSAR Comb. Sci., 26, 352 (2007).

17. L. Jäntschi, S. D. Bolboacă, R.E. Sestras, J. Mol. Mod., 16, 377 (2010).

18. M.H. Fatemi, Z. G. Chahi, SAR QSAR Environ. Res., 23, 155 (2012).

19. F. Li, X. Liu, L. Zhang, L. You, H. Wu, X. Li, J. Zhao, J. Yua, SAR QSAR Environ. Res., 22, 561 (2011).

20. L. Wang, X. Liu, Z. Shan, L. Shi, J. Environ. Sci., 22, 1544 (2010).

21. Xu, M., X. Liu, L. Wang, D. Wu, Z. Yang, B. Cui, J. Environ. Sci. Health, B44, 278 (2009)

22. L. Wang, X. H. Liu, D. Wu, M.Z. Xu, T. Sun, B.S. Cui, Z.F. Yang, SAR QSAR Environ. Res., 20, 91 (2009).

23. S. Arulmozhiraja, M. Morita, Chem. Res. Toxicol. 17, 348 (2004).

24. H. Inui, T. Wakai, K. Gion, Y-S. Kim, H. Eun, Chemosphere, 73, 1602 
(2008), and Supplementary Data

25. B. Bordás, I. Bélai, T. Kömíves, J. Agric. Food Chem., 59, 2863 (2011).

26. Y.C. Martin. Quantitative Drug Design. A critical Introduction. Dekker, New York, 1978.

27. D. Agin, L. Hersch, D. Holtzman, Proc. Natl. Acad. Sci. USA, 53, 952 (1965).

28. A. Cammarata, J. Med. Chem., 11, 1111 (1968).

29. F. Peradejordi, A.N. Martin, A. Cammarata, J. Pharm. Sci., 60, 576 (1971).

30. J.S. Gómez-Jeria, Int. J. Quant. Chem., 23, 1969 (1983). http://captura. uchile.cl/ jspui/handle/2250/14766.

31. J.S. Gómez-Jeria, Modeling the drug-receptor interaction in Quantum Pharmacology. In: Molecules in Physics, Chemistry and Biology, J. Maruani Ed., Kluwer Academic Publishers, Holland, 1989, Vol. IV, pp. 215-231. http://captura.uchile.cl/jspui/handle/2250/14915.

32. J.S. Gómez-Jeria, M. Ojeda-Vergara, J. Chil. Chem. Soc., 48, 119 (2003). http://captura.uchile.cl/jspui/handle/2250/15697.

33. J.S. Gómez-Jeria, J. Pharm. Sci., 71, 1423 (1982). http://captura.uchile.cl/ jspui/handle/2250/16536.

34. J.S. Gómez-Jeria, D. Morales-Lagos, J. Pharm. Sci., 73, 1725 (1984). http://captura.uchile.cl/jspui/handle/2250/14885.

35. J.S. Gómez-Jeria, J. Chil. Chem. Soc., 55, 381 (2010). http://captura. uchile.cl/jspui/handle/2250/13495.

36. J.S. Gómez-Jeria, F. Soto-Morales, J. Rivas, A. Sotomayor, J. Chil. Chem. Soc., 53, 1382 (2008). http://captura.uchile.cl/jspui/handle/2250/7314.

37. J.S. Gómez-Jeria, D. Morales-Lagos, B.K. Cassels, J.C. SaavedraAguilar, Quant. Struct.-Act. Relat. 5, 153 (1986). http://captura.uchile.cl/ jspui/handle/2250/14895.

38. J.S. Gómez-Jeria, B.K. Cassels, J.C. Saavedra-Aguilar, Eur. J. Med. Chem. 22, 433 (1987). http://captura.uchile.cl/jspui/handle/2250/16506.

39. J.S. Gómez-Jeria, M. Ojeda-Vergara, Int. J. Quant. Chem. 61, 997 (1997). http://captura.uchile.cl/jspui/handle/2250/14890.

40. J. Sangster, Octanol-Water Partition Coefficients: Fundamentals and Physical Chemistry, Wiley, New York, 1997.

41. KS Rogers, A Cammarata, Biochim. Biophys. Acta (BBA), 193, 22 (1969).
42. A. Cammarata, K.S. Rogers, J. Med. Chem., 14, 269 (1971).

43. K.S. Rogers, A, Cammarata, J. Med. Chem., 12, 692 (1969).

44. T.E. McKone, R.L. Maddalena, Environ. Toxicol. Chem. 26, 2494 (2007).

45. H.Inui, T.Wakai, K. Gion, K. Yamazaki, Y-S. Kim, H. Eun, Biosci. Biotechnol. Biochem., 75, 704 (2011).

46. K. Fukui, T. Yonezawa, C. Nagata, Bull. Chem. Soc. Jap., 27, 423 (1954).

47. K. Fukui, H. Fujimoto, Eds. Frontier Orbitals and Reaction Paths. World Scientific, Singapore, 1997.

48. W.D. Edwards, M.C. Zerner, 72, 347 (1987).

49. W.P. Anderson, W.D. Edwards, M.C. Zerner, Inorg. Chem. 28, 2728 (1986).

50. J.S. Gómez-Jeria, J. Pharm. Sci. 71, 1423 (1982). http://captura.uchile.cl/ jspui/handle/2250/16536.

51. J.S. Gómez-Jeria, L.A. Gerli-Candia, S.M. Hurtado, J. Chil. Chem. Soc. 49, 307 (2004). http://captura.uchile.cl/jspui/handle/2250/78.

52. F. Soto-Morales, J.S. Gómez-Jeria, J. Chil. Chem. Soc., 52, 1214 (2007) http://captura.uchile.cl/jspui/handle/2250/16905.

53. T. Bruna-Larenas, J.S. Gómez-Jeria, Int. J. Medicinal Chem., In press, 2012.

54. J.S. Gómez-Jeria, J. Computat. Theoret. Nanosci., 6, 1361 (2009).

55. A. E. Aliaga, H. Ahumada, K. Sepúlveda, J.S. Gómez-Jeria, B. WeissLópez, M.M. Campos-Vallette, J. Phys. Chem. C, 115, 3982 (2011).

56. C. Garrido, A. E. Aliaga, J. S. Gómez-Jeria, J. J. Cárcamo, E. Clavijo, M. M. Campos-Vallette, Vib. Spectr., 61, 94 (2012).

57. Hyperchem. Hypercube, Inc. 1115 NW 4th St. Gainesville, FL 32608 (USA).

58. Statistica. StatSoft, Inc. 2300 East 14th St. Tulsa, OK 74104 (USA).

59. G. Klopman, The Generalized Perturbation Theory of Chemical Reactivity and its Applications, in G. Klopman, Ed., Chemical Reactivity and Reaction Paths, Wiley-Interscience, New York, 1974, pp. 55-165.

60. G.R. Shaw, D.W. Connell, Chemosphere, 9, 731 (1980).

61. S. Matsuo, K. Yamakazi, K. Gion, H. Eun, H. Inui, J. Pestic. Sci., 36, 363 (2011). 